\title{
EFL Learners' Acceptance of Technology in a Computer-Assisted Language Learning (CALL) Context: The Role of Intrinsic-Extrinsic Motivation in English Learning
}

\author{
Liwei Hsu
}

\begin{abstract}
This study reports on an empirical analysis of the relationship between EFL learners' motivation variables and other variables of their uptake of computer-assisted language learning (CALL) with the application of the Technology Acceptance Model (TAM). Data were collected from 533 high school students in southern Taiwan through a questionnaire survey, and were analyzed through descriptive statistics and structural equation modeling (SEM). The results of the descriptive statistics revealed that participants were highly satisfied with the use of CALL. According to the SEM results, five of the eight proposed research hypotheses were supported: extrinsic and intrinsic motivation were both found to significantly affect perceived ease of use; however, the effect of extrinsic motivation was negative. In contrast, neither of these two motivation variables were significant to perceived usefulness. Perceived ease of use had a significant influence on perceived usefulness. Regarding how perceived ease of use and perceived usefulness affected the participants' attitude toward CALL, perceived usefulness was significant, while perceived ease of use was not. The participants' attitude was further discovered to significantly affect their satisfaction with CALL. The SEM analysis also revealed that some indirect effects might exist in the proposed model. The Sobel Test confirmed the roles that perceived ease of use and perceived usefulness played as mediators in the model.
\end{abstract}

Index Terms-Extrinsic motivation, intrinsic motivation, computer-assisted language learning, technology acceptance model, EFL learning.

\section{INTRODUCTION}

Along with the development of modern technology, the computer has become an important tool for students to acquire knowledge [1]. Teachers are also looking for innovative channels (e.g., information communication technology [ICT]) to engage students in instruction in meaningful ways [2]. English as a foreign language (EFL) education is no exception. ICT can be made beneficial to foreign language learning through creative pedagogy [3]. With a growing reliance on technologies, understanding factors affecting the user's acceptance of them is vital [4]. The functionalities of technologies will not be meaningful if teachers and students do not accept them in teaching and learning [5], [6]. Therefore, the individual's acceptance of a particular technology in an educational setting has attracted

Manuscript received August 23, 2016; revised November 1, 2016. This work was supported in part by the Ministry of Science and Technology (MOST 103-2511-S-328-001-MY2).

Liwei Hsu is with the National Kaohsiung University of Hospitality and Tourism, Kaohsiung city, Taiwan (e-mail: liweihsu@mail.nkuht.edu.tw). considerable attention in academia.

Regarding EFL education, learner motivation is one of the most significant factors for their attainment of English [7]-[11]. Although several pertinent studies examine motivation in language learning [12], little is known about the association of the individual learner's motivation and his/her acceptance of technology [13], particularly when the EFL learner's motivation factors are considered precedent variables in a robust framework applicable in the computer-assisted language learning (CALL) context.

As Lamb [14] and Li [15] posit, motivation is significantly influenced by contextual features. The present study therefore aims to adopt the Technology Acceptance Model (TAM) with motivational factors as external variables to examine the structural relationships between acceptance of technology and learner motivation. Two research questions are to be addressed:

1) What is the structural model with motivation factors for EFL learners' acceptance of technology for CALL?

2) How are EFL learners' motivation factors associated with other variables in TAM?

In order to answer the abovementioned questions, a review of pertinent studies on intrinsic/extrinsic motivation and TAM is presented. Consequently, an extended TAM with motivational variables is proposed. Having performed structural equation modeling, the results of hypotheses' testing are discussed. Limitations and suggestions for future work are then identified in the conclusion.

\section{BACKGROUND}

With the advent of the digital era, technologies have played a vital role in various aspects of learning including language learning. Computer-Assisted Language Learning (CALL) thus attracted many scholars' attention because many of them posited that computers may benefit EFL learners of different learning styles. However, any instruction will not work without learners' acceptance. When exploring the application of technologies in educational settings, the theoretical framework of Technology Acceptance Model (TAM) [16] has always been adopted by empirical studies. Two basic constructs of TAM are Perceived usefulness (PU) and perceived ease of use (PEU) [17]. Perceived usefulness represents a person's thoughts on to what extent technologies can be beneficial for their learning, and perceived ease of use represents learners' required efforts to successfully apply technologies in learning. According to previous work of TAM, PU and PEU will affect an individual's attitude of using 
technologies in learning and his/her continuing use [18]. This research project aims to explore learners' motivation as the external variable of TAM and understand the structural relationship between motivation and the usefulness and ease of use of English learning platform as well as the rest of variables of TAM.

As Ryan and Deci [19] indicate, motivation concerns all aspects of action and intention, and thus is highly valued in the fields of psychology and education. In the past three decades, more than 800 empirical works have been conducted to explore how an individual's intrinsic and extrinsic motivation affects behavior [20]. Motivation is defined by the present study as an individual learner's drive to learn the subject matter, which has always been acknowledged as a critical factor in learning [21], especially within the context of e-learning [22] and learning a second/foreign language [23], [24]. Nevertheless, motivation has not received enough attention in empirical studies of e-learning [25]. Two types of motivation - namely, intrinsic and extrinsic motivation-can engender an individual's final behavior [26]. In this paper, the intrinsic-extrinsic dichotomy is considered to be interchangeable with the integrative-instrumental one proposed by Eccles and Wigfield [27], Gardner [28], and Schmidt et al. [29].

An activity is generally considered to be intrinsically motivating if external reward is not necessary for learners to initiate and continue that activity [30]. Intrinsic motivation has been argued as the prime determinant in the participation of any activity [31]. Furthermore, it has been suggested by Bates [32] that the differences between extrinsic and intrinsic motivation should be identified for effective instructional design. The present research investigated both intrinsic and extrinsic motivation at the same time, since some EFL learners may be motivated by both simultaneously [33].

In the past years, more and more EFL programs have become administered through computers and ICT to enhance learning [34]. As there is a growing demand for e-learning, the need for empirical evidence on potential factors affecting the effectiveness of such courses is warranted [35]. The theoretical framework of the current research, as suggested by prior studies [36-37], is TAM, which is used to explore EFL learners' acceptance of technology in language learning, previous academic works have reported that PU and PEU of technology did affect EFL learners' attitudes toward using it (see [38]). Nevertheless, further exploration on the external variables, which may influence PU and/or PEU, is needed [39].

\section{PROCEDURE FOR PAPER SUBMISSION}

\section{A. Proposed Model and Research Hypotheses}

Based on the reviewed literature, this study used intrinsic and extrinsic motivation as determinants of TAM to examine the structural relationships. Davis et al. [40] integrated intrinsic and extrinsic motivation into TAM and discovered significant associations with PEU and PU, because people adopt technology for either its enjoyment or its usefulness [41]. Such results inspired other scholars [42] to follow up and conduct similar research, whereby the results seemed to be mixed. Therefore, the present study is based on the following hypotheses:

H1. EFL learners' extrinsic motivation for EFL learning has a significant effect on PU of CALL.

$\mathrm{H} 2$. EFL learners' intrinsic motivation for EFL learning has a significant effect on PU of CALL.

H3. EFL learners' extrinsic motivation for EFL learning has a significant effect on PEU of CALL.

H4. EFL learners' intrinsic motivation for EFL learning has a significant effect on PEU of CALL.

Concerning other variables of TAM, previous studies have suggested that PEU may significantly influence PU [43]; however, Saadé and Bahli [44] as well as Sánchez and Hueros [6] did not find support for such a claim. Thus, the present research proposes further hypotheses on the effect of PEU on PU, and both of these on attitudes towards CALL, formulated as follows:

H5. EFL learners' PEU has a significant effect on the PU of CALL.

H6. PEU has a positive effect on attitude towards using CALL.

H7. PU has a positive effect on attitude towards using CALL.

In the end, the present study would like to examine the relationship between EFL learners' attitudes towards using CALL and their satisfaction. In this study, the term satisfaction is defined as the extent to which EFL learners' belief that CALL is able to meet their needs is decisive to their continued usage [45]. Prior studies [46], [47] have postulated that an individual's perception of the quality of a system is positively correlated with his/her satisfaction. This has led us to propose also the following hypothesis:

H8. EFL learners' attitude toward CALL has a positive influence on user satisfaction.

\section{B. Research Context}

The CALL program adopted by the present study was MyET

(http://www.myet.com/MyETWeb/PersonalizedPage.aspx), a commercial program for EFL learning financed by National Kaohsiung University of Hospitality and Tourism. The use of MyET was a complementary mode of learning for the traditional face-to-face EFL teaching that began in September 2014 for a period of four months. The survey was undertaken in mid-December of 2014.

\section{Participants and Instrumentation}

Random sampling was adopted to recruit 796 students from the hospitality program from twenty high schools in Taiwan. In the end, a total of 533 participants completed the research process. Participation in the study was entirely voluntary and there were no punitive consequences for those who decided to drop out.

Instruments from the TAM studies and motivational theory were chosen and adapted to the present research context. EFL learners' intrinsic/extrinsic motivation for English learning was measured with the Academic Motivation Scale developed by Vallerand (1997), which has been widely used worldwide. Three items were used to measure the participant's intrinsic motivation for EFL learning (example item: "Because I 
experience pleasure while learning English"), while another three items were designed to evaluate his/her extrinsic motivation (example item: "Because I think being fluent in English will help me get a better job in the future").

To examine the participants' acceptance of the use of CALL for learning English, a scale was adopted from the work of Davis et al. [34] for this study: PEU (e.g., "It is easy for me to operate the technology to learn English"); PU (e.g., "Using ASR-based CAPT would enhance my learning English effectiveness"); ATU (e.g., "Learning English pronunciation via ASR-based CAPT is a positive idea"); and Satisfaction (e.g., "I am pretty satisfied with using technology to learn English"). The questionnaire items were translated into Chinese for the participants' ease of comprehension, and the accuracy of translation was subsequently ensured by matching a back-translated version with the original. Furthermore, the wording was examined and modified by experts. All of their suggestions were reflected in the revised questionnaire.

All of the questionnaire items were measured with a Likert 7-point scale, where $1=$ completely disagree and $7=$ completely agree. Concerning the analytic process of examining the research instrument, descriptive statistics were used to analyze the mean and the standard deviation of each item, while exploratory factor analysis (EFA) was performed to extract appropriate items. Accordingly, confirmatory factor analysis (CFA) was used to partial out items that did not meet the requirements of reliability and validity.

\section{RESULTS}

According to the two-step analytic procedure, the measurement model was firstly examined for the psychometric properties of parameters. Reliability, convergent validity, as well as discriminant validity of the research instrument were assured to obtain results with the desirable reliability and validity. Table I presents the descriptive statistics of questionnaire items, including the means and standard deviations of constructs.

TABLE I: DESCRIPTIVE STATISTICS OF CONSTRUCTS

\begin{tabular}{llc}
\hline Construct & Mean & Standard Deviation \\
\hline EM & 5.30 & 1.01 \\
IM & 5.79 & .99 \\
PEU & 5.81 & .92 \\
PU & 5.31 & 1.09 \\
ATU & 5.31 & 1.06 \\
SAT & 6.07 & .98 \\
\hline
\end{tabular}

From the information presented in Table I, it can be seen that participants of this study were keen to have a higher level of intrinsic motivation $(M=5.79)$. Extrinsic motivation was lower in intensity $(\mathrm{M}=5.30)$ and had greater standard deviation than intrinsic motivation $(\mathrm{SD}=1.01$ and .99 , respectively). PEU received the second highest mean score with the lowest standard deviation $(\mathrm{M}=5.81, \mathrm{SD}=.92)$, while PU and attitude (ATU) had the same mean score ( $\mathrm{M}=$ 5.31) and a similar standard deviation $(\mathrm{SD}=1.09$ and 1.06 , respectively). Participants were satisfied with the CALL program, with the highest mean score $(\mathrm{M}=6.07)$ and a low standard deviation $(\mathrm{SD}=.98)$.

\section{A. The Measurement Model}

Three psychometric properties of constructs should be examined for their convergent validity with factor loadings of each item, composite reliability (CR), and average variance extracted (AVE). All of the items have loading higher than .50, composite reliability of each construct is greater than .70, and the average variance extracted of most constructs is greater than .5 (with the exception of the construct of intrinsic motivation, which is slightly lower than .5). Nonetheless, the minimum acceptable AVE can be .3 , as long as three of five constructs have AVE above .5, which indicates that the convergent validity of the constructs of the present study were acceptable to excellent.

\begin{tabular}{|c|c|c|c|c|c|c|c|}
\hline Construct & $\begin{array}{l}\text { Construct } \\
\text { Code }\end{array}$ & $\begin{array}{l}\text { Item } \\
\text { Loading }\end{array}$ & AVE & MSV & ASV & CR & $\begin{array}{l}\text { Cronbach } \\
\alpha\end{array}$ \\
\hline Extrinsic & EMO1 & .63 & .51 & .37 & .09 & .76 & .75 \\
\hline Motivation & $\begin{array}{l}\text { EMO2 } \\
\text { EMO3 }\end{array}$ & $\begin{array}{l}.67 \\
.73\end{array}$ & & & & & \\
\hline Intrinsic & IMO1 & .59 & .45 & .37 & .09 & .70 & .67 \\
\hline Motivation & $\begin{array}{l}\text { IMO2 } \\
\text { IMO3 }\end{array}$ & $\begin{array}{l}.59 \\
.50\end{array}$ & & & & & \\
\hline Perceived & PEU1 & .60 & .58 & .52 & .23 & .85 & .85 \\
\hline Ease of Use & $\begin{array}{l}\text { PEU2 } \\
\text { PEU3 } \\
\text { PEU4 }\end{array}$ & $\begin{array}{l}.70 \\
.62 \\
.77\end{array}$ & & & & & \\
\hline Perceived & PU1 & .72 & .71 & .68 & .26 & .92 & .92 \\
\hline Usefulness & $\begin{array}{l}\text { PU2 } \\
\text { PU3 } \\
\text { PU4 } \\
\text { PU5 }\end{array}$ & $\begin{array}{l}.91 \\
.59 \\
.70 \\
.86\end{array}$ & & & & & \\
\hline $\begin{array}{l}\text { Attitude } \\
\text { toward }\end{array}$ & $\begin{array}{l}\text { ATU1 } \\
\text { ATU2 }\end{array}$ & $\begin{array}{l}.77 \\
.91\end{array}$ & .72 & .68 & .24 & .93 & .93 \\
\hline Technology & $\begin{array}{l}\text { ATU3 } \\
\text { ATU4 } \\
\text { ATU5 }\end{array}$ & $\begin{array}{l}.90 \\
.89 \\
.56\end{array}$ & & & & & \\
\hline Satisfaction & $\begin{array}{l}\text { SAT1 } \\
\text { SAT2 }\end{array}$ & $\begin{array}{l}.99 \\
.71\end{array}$ & .75 & .17 & .08 & .85 & .85 \\
\hline
\end{tabular}

Discriminant validity of all constructs should be assessed on the basis that the square root of the AVE of each construct 
should be higher than the correlation of any other constructs in the model [48]. Likewise, AVE should also be higher than Maximum Shared Variance (MSV) and Average Shared Variance (ASV) [49], and the results show that the discriminant validity of all constructs is adequate. Information on reliability and validity are presented in Table II.

\section{B. The Structural Model}

The structural model depicts the relationships between the proposed constructs of the research model to test whether they meet the stringent standard of .05 level of significance on the appropriate path coefficient [49]. The structural model was assessed with a maximum likelihood estimation, using AMOS 18.0. As suggested, criteria such as the nonnormed fit index (NNFI), the comparative fit index (CFI), and the root mean squared approximation of error (RMSEA) should be reported to examine the goodness of fit of the proposed model. The present model had NNFI $=.93, \mathrm{CFI}=.95$, and RMSEA $=.06$; moreover, $\mathrm{CMIN} / \mathrm{df}=2.70$ confirmed the goodness of fit as it was less than the threshold of 3.0.

After the goodness of model fit was ascertained, the analysis of the structural equation model was conducted. As shown in Fig. 1 and Table III, five of the eight proposed research hypotheses were supported. Extrinsic motivation and intrinsic motivation were both significant toward PEU ( $\beta=-.34$ and .34 , respectively) but not significant toward PU. The results indicate that the stronger EFL learners' extrinsic motivation and intrinsic motivation toward EFL learning, the stronger the effect of the PEU. Nevertheless, the insignificance of motivational variables toward PU was interesting.

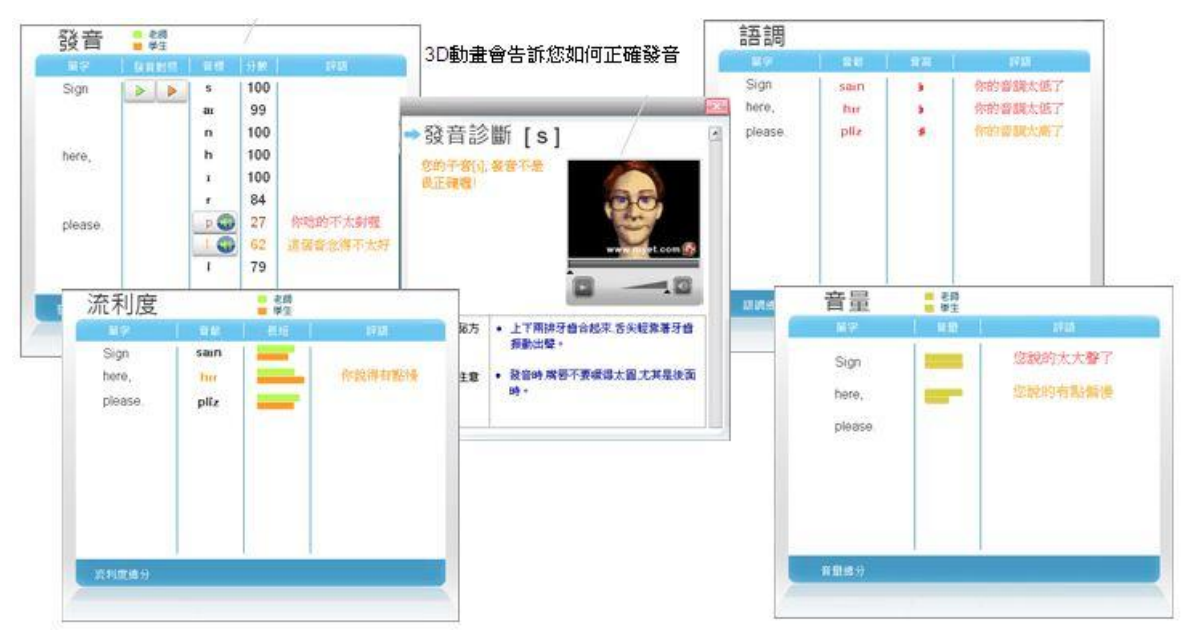

Fig. 1. A screenshot of MyET.

Most variables in TAM had a significant relationship, except the one between PEU and ATU. Specifically, PEU had a significant effect on PU $(\beta=.72, p<.001)$. The relationship between PU and ATU was also significant $(\beta=.76, p<.001)$, as was that of ATU and satisfaction (SAT) $(\beta=.32, p<.001)$.

Furthermore, results of SEM indicated possible indirect effects in the model. EM and IM seemed to have an indirect effect on PU through PEU as the mediator. In the same vein, PEU also had indirect effect on ATU through PU as the mediator. The mediation effects were examined using the Sobel Test.

TABLE III: SUMMARY OF THE RESULTS OF HYPOTHESIS TESTING

\begin{tabular}{lllll}
\hline & Hypothesis & $\beta$ & p-value & Supported \\
\hline H1 & PU <-- EM & -.01 & .87 & No \\
H2 & PU <-- IM & -.00 & .96 & No \\
H3 & PEU <-- EM & -.34 & $* * *$ & Yes \\
H4 & PEU <-- IM & .34 & $* *$ & Yes \\
H5 & PU <-- PEU & .72 & $* * *$ & Yes \\
H6 & ATU <-- PEU & .09 & .06 & No \\
H7 & ATU <-- PU & .76 & $* * *$ & Yes \\
H8 & SAT <-- ATU & .32 & $* * *$ & Yes \\
\hline
\end{tabular}

Note: $* p<.05, * * p<.01, * * * p<.001$

The results of the Sobel Test suggest that the associations between extrinsic motivation and PU, and between intrinsic motivation and PU, were significantly mediated by PEU $(Z=$
-3.43 and 2.83, respectively, $p=.00)$. The mediation effect of PU between PEU and ATU was also significant $(Z=8.38, \mathrm{p}$ $=.00)$. In summary, the results of the Sobel Test indicate that all the mediation effects were significant.

\begin{tabular}{cclc}
\multicolumn{4}{c}{ TABLE IV: SOBEL TEST FOR MEDIATION EFFECTS } \\
\hline Path & Sobel Test Statistic $(Z)$ & $\begin{array}{l}\text { Standard } \\
\text { Deviation }\end{array}$ & P value \\
& & .08 & $.00 * * *$ \\
PU <-- PEU <-- EM & -3.43 & .20 & $.00 * * *$ \\
PU <-- PEU <-- IM & 2.83 & .07 & $.00 * * *$ \\
ATU <-- PU <-- PEU & 8.38 &
\end{tabular}

\section{DISCUSSIONS}

In the field of EFL teaching and learning, CALL has been popularly adopted for its functionality; nevertheless, EFL learners' acceptance of CALL still calls for more empirical work. The descriptive statistics of this study have uncovered that EFL learners in Taiwan had slightly greater intrinsic motivation than extrinsic motivation. Such a result is in contrast with Liu and Chen's 2015 study [50], which found that vocational high school students in Taiwan tended to be extrinsically motivated to engage in EFL learning. However, they did not specify the educational background of their participants. In the present study, all of the participants were students of a hospitality program, who might consider EFL learning to be inherently interesting or enjoyable.

With the administration of SEM, the results of the present 
research did reveal some important information about the EFL learners' motivation toward English learning and their acceptance of CALL. Firstly, both extrinsic and intrinsic motivation had significant effects over PEU, which was partially in line with the findings of Fagan et al. [42]. In their study, they found that both intrinsic and extrinsic motivation were positively and significantly related to PEU, whereas the current study found that the relationship between EFL learners' extrinsic motivation and PEU was negative. In other words, the more an EFL learner is extrinsically motivated, the less important he/she would consider PEU. One of the possible explanations may be that no feasible reward had been given to the participants and the use of CALL might therefore be perceived as a waste of their time. Another reason may be that if they thought CALL is too easy for them to use, it may not be challenging to them, and thus the extrinsic motivation for being respected by others (i.e., their reputation, as proposed by Yang \& Lai in 2010 [51]) would not be relevant

On the other hand, if an individual's level of intrinsic motivation is high, it implies that he/she enjoys the online activity very much and thus will eventually dedicate time and effort to understanding how to solve the problems when using the technology [52]. The Cognitive Evaluation Theory also asserts that a higher level of intrinsic motivation will eventually generate PU [53]. Nevertheless, the results of the present study did not find any significant effect that an EFL learner's intrinsic and extrinsic motivation of learning English leads to PU of a CALL program. A possible reason might be that in Asian countries, EFL teaching and learning are mainly for examination, and whether CALL can help to achieve higher scores matters to learners [15], [54]; however, the CALL in this study was not specifically for examination preparation. If they perceived that the CALL program could not help them to get a good score, their extrinsic motivation would naturally have been lowered. For learners whose motivation was intrinsic, their motivation to learn English would not have been influenced by how helpful CALL can be to them. In other words, they will figure out an effective way to learn English regardless of whether it is really useful to them.

Nevertheless, the effects of motivational variables toward PU were mediated by PEU of CALL. Such results echo what Caniëls et al. [53] claim: that an individual will consider any technology to be beneficial to him/her only when he/she feels competent in using it. For this reason, for the course designer of CALL, it is advisable to take the end-users' level of proficiency in both language and digital literacy into consideration when creating content. In terms of digital literacy, the ease of use should be moderately challenging but not very far beyond the users' ability, for the sake of learners whose motivation is extrinsic. Future research may be designed to explore this issue from the perspective of Self-Determination Theory. Boekaerts [27] argue that learners' motivation is dynamic and thus in constant flux, because their psychological needs are varied according to changing needs and goals. Future studies are advised to adopt longitudinal design to explore the dynamic changes of motivation toward technology-enhanced hospitality education.

In terms of how PEU interrelates with PU, the findings of the present study support previous studies by Caniëls et al. [53] and Fagan et al. [45], which asserted that PEU positively and significantly influences PU. Moreover, turning now to the effect of PU and PEU on attitude toward CALL, it has been shown that PU had a direct impact on attitude, whereas PEU only indirectly influenced attitude through the mediation of PU. Such results support previous studies that asserted that PEU has an indirect effect on attitude through the mediation of PU [3]. Nevertheless, it should be noted that ease of use cannot be overlooked by the practitioners of CALL. When considering the ease of use of CALL, its usefulness also needs to be prioritized.

Successful design and implementation of e-learning depends greatly upon learners' satisfaction with the system [45], [54], [55], and the results of descriptive statistics reported that the mean score of participants' satisfaction toward CALL was the highest (6.07 out of 7). The structural analysis also confirmed that EFL learners' attitude toward CALL significantly led to their satisfaction, as previous studies have pointed out. Lai and Hwang [56] therefore recommend that appropriately designed and implemented computer-assisted learning will not only promote learners' attitude and satisfaction, but also improve their learning achievement.

\section{CONCLUSION AND IMPLICATION}

The current study has highlighted the role of EFL learners' motivation factors in their acceptance of CALL. The results of this study revealed that participants were satisfied with CALL in the present study. Overall, participants had a slightly higher intensity of intrinsic motivation than extrinsic motivation. While motivational variables are integrated in TAM, structural equation modeling was employed to explore the casual relationship of the variables. Both motivational variables (i.e., extrinsic motivation and intrinsic motivation) were found to be significant to the PEU of CALL, yet insignificant to PU. However, the effect of extrinsic motivation on PEU was negative. PEU was significantly and positively influential on PU, which was found to be significant to attitude. Nevertheless, PEU was not itself significant to attitude, which was significant to participants' satisfaction. Results of SEM indicate the possible indirect effects in the model. The Sobel Test reported that both motivational variables had an indirect effect on PU through the mediation of PEU. By the same token, with the mediation of PU, PEU was also found to have an indirect effect on attitude. Findings elicited by the present study can be contributed to the academia to extend the current understanding on the importance of a learner's motivation when computers/technologies are designed to be used in EFL teaching and learning.

Results of the present research offer implications for practitioners. Firstly, it is advised that the contents and design of CALL be moderately challenging for EFL learners (see also [57]), and the issue of balancing challenge and ease of use should therefore be considered. Concerning the roles that motivation variables play in EFL learners' acceptance of CALL, as Dörnyei and Csizér [58] have suggested, 
motivation is only indirectly related to a language learner's learning achievement: it cannot be accountable for how successfully a language learner is able to acquire the target language, with or without the help of CALL. Practitioners should pay close attention to EFL learners' language learning strategy to better comprehend the holistic situation of the relationship between motivation and learning achievement [59]. Future studies may use language learning strategy as a moderator or mediator in the model to examine its role in EFL learners' acceptance of CALL. Language learning strategy can also be considered a predecessor of motivation, because using language learning strategies effectively may lead to stronger motivation in language learning [60].

Finally, the present research raises some suggestions for future research because of the limits of this study. Firstly, this work was conducted at the Taiwanese secondary education level, and the application of this model in various settings may identify currently missing points and further improve the generalizability of this model. Additionally, designing a longitudinal study to examine the dynamic attribute of motivation would provide a complementary perspective to the present study. Last but not least, taking other variables such as the EFL learner's level of proficiency in English [7] and age and maturity of participants [15] into account in the model would be a productive direction for future research, since it is a decisive factor in learners' motivation in EFL learning.

\section{REFERENCES}

[1] A. R. Artino, "Motivational beliefs and perceptions of instructional quality: Predicting satisfaction with online training," Journal of Computer Assisted Learning, vol. 24, no. 3, pp. 260-270, 2008.

[2] C. Orsini and P. Evans, "Social media as a teaching strategy: Opportunities and barriers," Advances in Health Professions Education, vol. 1, no. 1, pp. 44-46, 2015.

[3] R. Cakır and E. Solak, "Attitude of Turkish EFL learners towards e-learning through Tam model," Procedia-Social and Behavioral Sciences, vol. 176, pp. 596-601, 2015.

[4] M. Y. Yi and Y. Hwang, "Predicting the use of web-based information systems: self-efficacy, enjoyment, learning goal orientation, and the technology acceptance model," International Journal of Human-Computer Studies, vol. 59, no. 4, pp. 431-449, 2003.

[5] M. K. Lee et al., "Acceptance of Internet-based learning medium: The role of extrinsic and intrinsic motivation," Information \& Management vol. 42, no. 8, pp. 1095-1104, 2005.

[6] R. A. Sánchez and A. D. Hueros, "Motivational factors that influence the acceptance of Moodle using TAM." Computers in Human Behavior, vol. 26, no. 6, pp. 1632-1640, 2010.

[7] J. M. Carreira, "Relationship between motivation for learning EFL and intrinsic motivation for learning in general among Japanese elementary school students," System, vol. 39, no. 1, pp. 90-102, 2011.

[8] Z. Dörnyei, The Psychology of Second Language Acquisition, Oxford: Oxford University Press, 2009.

[9] J. Iwaniec, "Motivation of pupils from southern Poland to learn English," System, vol. 45, pp. 67-78, 2014.

[10] H. Xu and Y. Gao, "The development of English learning motivation and learners' identities: A structural equation modeling analysis of longitudinal data from Chinese universities," System, vol. 47, pp. 102-115, 2014.

[11] X. Xu, "The relationship between language learning motivation and the choice of language learning strategies among Chinese graduates," International Journal of English Linguistics, pp. 203-212, 2011.

[12] A. Ghanizadeh and S. Jahedizadeh, "Context-specific dynamics of demotivators in foreign language education," International Journal of Research Studies in Language Learning, vol. 4, no. 5, pp. 1-10, 2015.

[13] Y. Lee, J. Lee, and Y. Hwang, "Relating motivation to information and communication technology acceptance: Self-determination theory perspective," Computers in Human Behavior, vol. 51, pp. 418-428, 2015.
[14] M. Lamb, "A self system perspective on young adolescents' motivation to learn English in urban and rural settings," Language Learning, vol. 62, no. 4, pp. 997-1023, 2012.

[15] Q. Li, "Differences in the motivation of Chinese learners of English in a foreign and second language context," System, vol. 42, pp. 451-461, 2014.

[16] H.-H. Chung et al., "A study of EFL college students' acceptance of mobile learning," Procedia-Social and Behavioral Sciences, vol. 176, pp. 333-339, 2015.

[17] F. D. Davis et al., "Extrinsic and intrinsic motivation to use computers in the workplace," Journal of Applied Social Psychology, vol. 22, no. 14, pp. 1111-1132, 1992.

[18] M. H. Fagan et al., "Exploring the intention to use computers: An empirical investigation of the role of intrinsic motivation, extrinsic motivation, and perceived ease of use," Journal of Computer Information Systems, vol. 48, no. 3, pp. 31-37, 2008.

[19] R. M. Ryan and E. L. Deci, "Self-determination theory and the facilitation of intrinsic motivation, social development, and well-being," American Psychologist, vol. 55, no. 1, pp. 68-78, 2000.

[20] M.-H. Hsu et al., Knowledge sharing behavior in virtual communities: The relationship between trust, self-efficacy, and outcome expectations. International Journal of Human-Computer Studies, vol. 65, no. 2, pp. 153-169, 2007.

[21] K.-C. Chen and S.-J. Jang, "Motivation in online learning: Testing a model of self-determination theory," Computers in Human Behavior, vol. 26, no. 4, pp. 741-752, 2010.

[22] A. Jones and K. Issroff, "Learning technologies: Affective and social issues in computer-supported collaborative learning," Computers \& Education, vol. 44, no. 4, pp. 395-408, 2005.

[23] F. M. Al-Khasawneh and M. A. Al-Omari, "Motivations towards learning English: The case of Jordanian gifted students," International Journal of Education, vol. 7, no. 2, pp. 306-321, 2015.

[24] D. Lasagabaster and R. L. Beloqui, "The impact of type of approach (CLIL versus EFL) and methodology (book-based versus project work) on motivation," Porta Linguarum, vol. 23, pp. 41-57, 2015.

[25] R. M. Ryan and E. L. Deci, "Intrinsic and extrinsic motivations: Classic definitions and new directions," Contemporary Educational Psychology, vol. 25, no. 1, pp. 54-67, 2000.

[26] M. Boekaerts, Motivation to Learn, Genève: International Bureau of Education, 2002

[27] J. S. Eccles and A. Wigfield, "Motivational beliefs, values, and goals," Annual Review of Psychology, vol. 53, no. 1, pp. 109-132, 2002.

[28] R. C. Gardner, "Motivation and second language acquisition," Porta Linguarum, vol. 8, pp. 9-12, 2007.

[29] R. Schmidt et al., "Foreign language motivation: Internal structure and external connections," Language Learning Motivation: Pathways to the New Century, vol. 2, pp. 9-70, 1996.

[30] M. Boekaerts, Motivation to Learn, Genève: International Bureau of Education, 2002

[31] M. Gagné and E. L. Deci, "Self-determination theory and work motivation," Journal of Organizational Behavior, vol. 26, no. 4, pp. 331-362, 2005.

[32] C. M. F. Bates, "Learner characteristics and motivation: How to achieve efficient and effective learning," Collected Essays on Learning and Teaching, vol. 8, pp. 165-170, 2015.

[33] Y. Malhotra, D. F. Galletta, and L. J. Kirsch, "How endogenous motivations influence user intentions: Beyond the dichotomy of extrinsic and intrinsic user motivations," Journal of Management Information Systems, vol. 25, no. 1, pp. 267-300, 2008.

[34] V. Barkoukis et al., "The assessment of intrinsic and extrinsic motivation and amotivation: Validity and reliability of the Greek version of the Academic Motivation Scale," Assessment in Education: Principles, Policy \& Practice, vol. 15, no. 1, pp. 39-55, 2008.

[35] U. D. Ehlers and J. R. Hilera, "Special issue on quality in e-learning," Journal of Computer Assisted Learning, vol. 28, no. 1, pp. 1-3, 2012.

[36] F. D. Davis, R. P. Bagozzi, and P. R. Warshaw, "User acceptance of computer technology: A comparison of two theoretical models," Management Science, vol. 35, no. 8, pp. 982-1003, 2015.

[37] H.-H. Chung, S.-C. Chen, and M.-H. Kuo, "A study of EFL college students' acceptance of mobile learning," Procedia-Social and Behavioral Sciences, vol. 176, pp. 333-339, 2015.

[38] B. Y. Mah and A. N. Er, "Writing web logs in the ESL Classroom: A study of student perceptions and the technology acceptance model," Asian Journal of University Education, vol. 5, no. 1, pp. 47-70, 2009.

[39] G. W.-H. Tan, K.-B. Ooi, L.-Y. Leong, and B. Lin, "Predicting the drivers of behavioral intention to use mobile learning: A hybrid SEM-Neural Networks approach," Computers in Human Behavior, vol. 36, pp. 198-213, 2014. 
[40] F. D. Davis et al., "Extrinsic and intrinsic motivation to use computers in the workplace," Journal of Applied Social Psychology, vol. 22, no. 14, pp. 1111-1132, 1992.

[41] T. S. Teo et al., "Intrinsic and extrinsic motivation in Internet usage," Omega, vol. 27, no. 1, pp. 25-37, 1999.

[42] M. H. Fagan, S. Neill, and B. R. Wooldridge, "Exploring the intention to use computers: An empirical investigation of the role of intrinsic motivation, extrinsic motivation, and perceived ease of use," Journal of Computer Information Systems, vol. 48, no. 3, pp. 31-37, 2008.

[43] C.-K. Chang and C.-K. Hsu, "A mobile-assisted synchronously collaborative translation-annotation system for English as a foreign language (EFL) reading comprehension," Computer Assisted Language Learning, vol. 24, no. 2, pp. 155-180, 2011.

[44] R. Saadé and B. Bahli, "The impact of cognitive absorption on perceived usefulness and perceived ease of use in on-line learning: an extension of the technology acceptance model," Information \& management, vol. 42, no. 2, pp. 317-327, 2005.

[45] Y.-W. Liao et al., "Exploring the antecedents of collaborative learning performance over social networking sites in a ubiquitous learning context," Computers in Human Behavior, vol. 43, pp. 313-323, 2015.

[46] R. D. Freeze et al., "IS success model in e-learning context based on students' perception," Journal of Information Systems Education, vol. 21, no. 2, pp. 173-184, 2010.

[47] . C. Roca et al., "Understanding e-learning continuance intention: An extension of the technology acceptance model," International Journal of Human-Computer Studies, vol. 64, no. 8, pp. 683-696, 2006.

[48] W. W. Chin, "Issues and opinion on structural equation modeling," MIS Quarterly, vol. 22, no. 1, pp. vii-xvi, 1998.

[49] J. F. Hair et al., Multivariate Data Analysis (7th ed.), Upper Saddle River, NJ: Prentice-Hall, Inc., 2010.

[50] H.-J. Liu and C.-W. Chen, "A comparative study of foreign language anxiety and motivation of academic- and vocational-track high school students," English Language Teaching, vol. 8, no. 3, pp. 193-204, 2015.

[51] H.-L. Yang and C.-Y. Lai, "Motivations of Wikipedia content contributors," Computers in Human Behavior, vol. 26, no. 6, pp 1377-1383, 2010.

[52] P. Ji et al., "Love Internet, love online content: Predicting Internet affinity with information gratification and social gratifications," Internet Research, vol. 23, no. 4, pp. 396-413, 2013.
[53] M. C. Caniëls et al., "Explaining the internet usage of SMEs: The impact of market orientation, behavioural norms, motivation and technology acceptance," Internet Research, vol. 25, no. 3, pp. 358-377, 2015 .

[54] C.-M. Chiu et al., "An empirical analysis of the antecedents of web-based learning continuance," Computers \& Education, vol. 49, no. 4, pp. 1224-1245, 2007.

[55] S. Y. McGorry, "Measuring quality in online programs," The Internet and Higher Education, vol. 6, no. 2, pp. 159-177, 2003.

[56] C.-L. Lai and G.-J. Hwang, “A spreadsheet-based visualized Mindtool for improving students' learning performance in identifying relationships between numerical variables," Interactive Learning Environments, vol. 23, no. 2, pp. 230-249, 2015.

[57] X. Wu, "Intrinsic motivation and young language learners: The impact of the classroom environment," System, vol. 31, no. 4, pp. 501-517, 2003.

[58] Z. Dörnyei and K. Csizér, Motivation, Language Attitudes and Globalisation: A Hungarian Perspective, Clevedon, England: Multilingual Matters, 2006.

[59] Z. Dörnyei, "Attitudes, orientations, and motivations in language learning: Advances in theory, research, and applications," Language Learning, vol. 53, no. S1, pp. 3-32, 2003.

[60] L. Vandergrift, "Relationships among motivation orientations, metacognitive awareness and proficiency in L2 listening," Applied Linguistics, vol. 26, no. 1, pp. 70-89, 2005.

Liwei Hsu is a professor of Graduate Institute of Hospitality at National Kaohsiung University of Hospitality and Tourism. Professor Hsu earned his doctorate in education at the University of southern California, Los Angeles, USA. His research interests focus of CALL as well as the application of ICT in hospitality education.

He currently serves as the dean of hospitality management in National Kaohsiung University of hospitality and Tourism, Kaohsiung City, Taiwan. He has published articles in many peer-review journals including Computer Assisted Language Learning and Australesan Journal of Educational Technology.

Professor Hsu also serves as a member of SIG for Hospitality Education Research under the supervision of the Ministry of Science and Technology of Taiwan. 